\title{
O PROJETO DE EDUCAÇÃO AMBIENTAL NAS ESCOLAS MUNICIPAIS DE ENSINO FUNDAMENTAL I DE TEMPO INTEGRAL DE ILHA SOLTEIRA/SP
}

\author{
Mariana Vasconcelos da Silva ${ }^{1}$ \\ Juliana de Assis ${ }^{2}$ \\ Aline Patrícia Maciel ${ }^{3}$
}

\begin{abstract}
RESUMO
O presente trabalho apresenta o projeto de Educação Ambiental desenvolvido nas escolas municipais de ensino fundamental I de tempo integral do município de llha Solteira/SP. Para tal, foram realizados pesquisa bibliográfica para conceituar e destacar as leis que regem o ensino de Educação Ambiental com o propósito de contribuir com a conscientização dos alunos e permitir o desenvolvimento de pensamentos críticos quanto as questões ligadas a preservação do meio ambiente. Devido aos problemas ambientais causados pelas ações humanas, visou desenvolver os conteúdos relacionados a água, energia, lixo e reciclagem, fauna e flora, higiene, alimentação saudável e cidadania, além de saídas de campo para melhor concretização da aprendizagem no intuito de promover mudanças de hábitos e buscar soluções sustentáveis para a melhoria de vida no planeta Terra.
\end{abstract}

PALAVRAS-CHAVE: Educação Ambiental. Aprendizagem. Conscientização.

\section{THE PROJECT OF ENVIRONMENTAL EDUCATION AT FULL-TIME ELEMENTARY PUBLIC SCHOOL - I IN ILHA SOLTEIRA, SP, BRAZIL}

\begin{abstract}
The present work presents the environmental education project developed at full-time elementary public schools in the city of llha Solteira / SP. To this end, were performed bibliographical research to conceptualize and highlight the laws governing environmental education teaching in order to contribute to the awareness of students and enable the development of critical thinking about issues related to preserving the environment. Because of the environmental problems caused by human actions, aimed at developing contents related to water, energy, garbage and recycling, fauna and flora, hygiene,, healthy eating and citizenship, as well as field trips to better implementation of learning in order to promote change habits and seek sustainable solutions for the betterment of life on planet Earth.
\end{abstract}

KEY-WORDS: Environmental Education. Learning. Awareness.

\footnotetext{
${ }^{1}$ Licenciatura e Bacharelado em Geografia pela instituição UNESP/FCT, mestranda em Geografia pela UFMS campus de Três Lagoas/MS. Professora Municipal de llha Solteira/SP. E-mail: maryvasc@hotmail.com

${ }^{2}$ Licenciatura em Ciências Biológicas pela UNESP/FEIS, mestre em Ciência Animal pela UNESP campus de Araçatuba/SP. Professora Municipal de Ilha Solteira/SP. E-mail:

jassis_assis@yahoo.com.br

${ }^{3}$ Licenciatura em Geografia pela UFMS/CPTL, especialização em Psicopedagogia pela UNITOLEDO de Araçatuba/SP, pós-graduanda em Educação Básica no Campo pela UFMS/CPTL. Professora Municipal de Ilha Solteira/SP. E-mail: alinepmaciel@yahoo.com.br
} 


\section{LA EDUCACIÓN PROYECTO DE EDUCACIÓN AMBIENTAL EN LAS ESCUELAS MUNICIPALES PRIMARIA I DE TIEMPO COMPLETO DEL ILHA SOLTEIRA/ SP}

\section{RESUMEN}

Este artículo presenta el proyecto de educación ambiental desarrollado en las escuelas públicas primarias y de tiempo completo en la ciudad de Ilha Solteira / SP. Para ello, llevamos a cabo la literatura de conceptualizar y poner de relieve las leyes que rigen la enseñanza de la educación ambiental con el fin de contribuir a la sensibilización de los estudiantes y permitir el desarrollo de un pensamiento crítico acerca de las cuestiones relacionadas a la preservación del medio ambiente. Debido a los problemas ambientales causados por la acción humana, con el objetivo de desarrollar contenido relacionado de agua, la energía, los residuos y el reciclaje, la fauna y la flora, la higiene, la alimentación saludable y la ciudadanía, así como excursiones a una mejor aplicación de aprendizaje con el fin de promover el cambio hábitos y buscar soluciones sostenibles para el mejoramiento de la vida en el planeta Tierra.

PALABRAS-CLAVE: Educación Ambiental. aprendizaje. concientización

\section{INTRODUÇÃO}

Após a Revolução Industrial nos séculos XVIII e XIX, houveram mudanças significativas por meio da implementação das máquinas e posteriormente das tecnologias, que ocasionaram o aumento e o uso exagerado dos recursos naturais para a manutenção desse sistema, gerando impactos de grandes proporções no meio ambiente.

Atualmente vivemos numa sociedade de consumo exacerbado o qual é incentivado pelo sistema capitalista que visa principalmente o lucro em detrimento da degradação ambiental. Consequentemente, houve o aumento dos problemas socioambientais e econômicos, acarretados pelas disputas dos recursos naturais renováveis e dos recursos naturais não renováveis que são finitos na natureza.

A Educação Ambiental (EA) surgi a partir dos anos 70, devido à necessidade de conscientização da população quanto aos problemas ambientais. Para auxiliar nesse processo de conscientização, a escola seria de grande importância no processo de formação social quanto ambiental dos alunos.

Dessa maneira, a Educação Ambiental integrou-se na educação brasileira, abrangendo todos os níveis de escolaridade, desde a educação básica à educação superior, inserida como parte diversificada ou como tema transversal nos Parâmetros Curriculares Nacionais (PCN) reafirmando a necessidade de se 
trabalhar os temas ligados ao meio ambiente nas escolas e principalmente de forma interdisciplinar para o desenvolvimento da consciência ambiental.

Um dos modos de aplicar a EA dentro das escolas é a partir de projetos que possuam atividades dinâmicas, unindo teoria e prática para garantir a sensibilização dos alunos quanto aos problemas ambientais. Discutiremos, portanto, como a EA foi implanta no Brasil e nas escolas, ao analisarmos a Lei № 9.795/99 da Política Nacional de Educação Ambiental (PNEA), em conformidade com a Lei № 9.394 das Diretrizes e Bases da Educação Nacional (LDB), também a Diretrizes Curriculares Nacionais para a Educação Ambiental, objetivando destacar neste trabalho o projeto realizado nas escolas municipais de Ilha Solteira/SP no qual são promovidas ações educativas que contribuem para a conscientização e o desenvolvimento de pensamentos críticos nos alunos quanto as questões ligadas a preservação do meio ambiente e a sustentabilidade.

\section{EDUCAÇÃO AMBIENTAL}

As ações humanas nos últimos anos causaram grande prejuízo aos recursos naturais proporcionados pelo desenvolvimento capitalista sem um planejamento ou manejo adequado. Diante deste cenário é fundamental que a EA esteja presente em todos os níveis escolares para desenvolver a conscientização dos alunos quanto a preservação do meio ambiente.

Segundo Abílio (2008) destaca que:

EA é um processo em que se busca observar a preocupação dos indivíduos e comunidades para as questões ambientais, fornecendo informações e contribuindo para um Desenvolvimento Sustentável de uma forma crítica. (ABíLIO, Francisco, 2008, p.328).

A Constituição Federal já destaca no Art. 225 que todos têm direito ao meio ambiente ecologicamente equilibrado, bem de uso comum do povo e essencial à sadia qualidade de vida, impondo-se ao Poder Público e à coletividade o dever de defendê-lo e preservar para as presentes e futuras gerações. (BRASIL,1988), demonstrando a importância de preservar e restaurar, controlar a produção, proteger a fauna e flora e promover a educação ambiental. 
A Educação brasileira é regida pela Lei no 9.394/96 de Diretrizes e Bases da Educação (LDB), com base nos princípios presentes na Constituição Federal Brasileira (BRASIL, 1988). No Art. 26 Lei no 9.394/96, os currículos da educação infantil, do ensino fundamental e do ensino médio devem ter base nacional comum, a ser complementada, em cada sistema de ensino e, por uma parte diversificada. Destacam-se no inciso $\S 7^{\circ}$ os currículos do Ensino Fundamental e Médio devem incluir os princípios da proteção e defesa civil e a educação ambiental de forma integrada aos conteúdos obrigatórios (BRASIL, 1996).

A implementação efetiva da Lei № 9.795/99 da Política Nacional de Educação Ambiental (PNEA) conceitua a EA:

Art. $1^{\circ}$ Entendem-se por educação ambiental os processos por meio dos quais $o$ indivíduo e a coletividade constroem valores sociais, conhecimentos, habilidades, atitudes e competências voltadas para a conservação do meio ambiente, bem de uso comum do povo, essencial à sadia qualidade de vida e sua sustentabilidade.

Art. $2^{\circ}$ A educação ambiental é um componente essencial e permanente da educação nacional, devendo estar presente, de forma articulada, em todos os níveis e modalidades do processo educativo, em caráter formal e não-formal. (BRASIL,1999)

$\mathrm{Na}$ perspectiva educativa, a EA deve ser desenvolvida de maneira interdisciplinar, para refletir essas questões ambientais de forma a envolver os educandos com aulas práticas e dinâmicas.

Ainda segundo a Lei 9.795/99 da PENEA:

Também são princípios básicos da EA, constituir um processo contínuo e permanente, através de todas as fases do ensino formal e não formal, aplicando um enfoque interdisciplinar aproveitando o conteúdo específico de cada disciplina, de modo que os discentes se identifiquem com as condições ambientais de outras regiões geográficas, concentrando-se nas condições ambientais atuais, tendo em conta também a perspectiva histórica. Utilizar diversos ambientes educativos e uma ampla gama de métodos para comunicar e adquirir conhecimentos sobre o meio ambiente, acentuando devidamente as atividades práticas e as experiências pessoais.

É importante que esse processo participativo seja permanente, de maneira que não seja apenas e exclusivamente informativa, mas que desenvolver em todos uma consciência crítica sobre a problemática ambiental, ultrapassando os muros da escola. Sendo assim, é fundamental desenvolver projetos escolares com atividades 


\section{Periódico Eletrôntico}

Fórum Ambiental

da Alta Paulista
Volume 11, Número 04, 2015

Educação Ambiental

diferenciadas para promover a aprendizagem dos alunos e contribuir para a formação de cidadãos responsáveis.

\section{METODOLOGIA}

Em consonância com a Lei Municipal № 1658 de 02 de Setembro de 2009 a EA foi implantada no município de Ilha Solteira - SP localizado na Região Noroeste do Estado de São Paulo com 26.242 habitantes (IBGE, 2014) para ser desenvolvida nas Escolas Municipais de Ensino Fundamental I: EMEF Prof. a Aparecida Benedita Brito da Silva (ABBS), EMEF Prof. - Lúcia Maria Donato Garcia (LMDG) e EMEF Prof. Paulo Freire.

Contemplando as necessidades atuais de se fazer a conscientização da população para que haja a efetiva mudança de hábitos e atitudes sustentáveis foi elaborado um Planejamento Escolar de EA com a proposta de desenvolver, nas escolas, práticas pedagógicas de incentivo à preservação do meio ambiente com as turmas de $1^{\circ}$ ao $5^{\circ}$ ano, entre os anos de 2012 a 2015, com aproximadamente 1000 alunos por ano letivo. Os conteúdos foram trabalhados em aulas de 50 minutos semanais, no período matutino, com todas as séries e foram desenvolvidos por professores especialistas com licenciatura em Ciências Biológicas e Geografia.

A fim de alcançar os objetivos propostos pelo projeto foram trabalhados os problemas ambientais mais relevantes da atualidade dentre os quais: a produção e as formas de economia de Energia Elétrica; os sistemas de captação, tratamento e distribuição de Água e Esgoto, também as dicas de economia de água e a importância da preservação de regiões de mananciais como as Bacias Hidrográficas e de Mata Ciliar; a Fauna e Flora brasileira e as principais espécies de animais em extinção; os tipos de Resíduos Sólidos, descarte correto de lixo, locais de destinação final do Lixo e os três "R" (Reduzir, Reutilizar e Reciclar); as formas corretas de Higienização Corporal; a importância de se fazer uma Alimentação Saudável; e a Educação no Trânsito e a Cidadania em prol da paz na sociedade. 


\section{RESULTADOS}

A aprendizagem só é efetiva quando o cidadão adquire conhecimentos e os coloca em prática no seu dia a dia. Assim, o Projeto de Educação Ambiental foi elaborado com o propósito de desenvolver atividades de sensibilização para promover a conscientização dos alunos quanto aos problemas ambientais e a sustentabilidade, garantindo assim, uma melhor qualidade de vida às gerações futuras.

As atividades de EA foram desenvolvidas nas escolas municipais em parcerias com instituições públicas e também com o apoio da comunidade.

Seguem as atividades desenvolvidas nas EMEFs:

\section{Água}

A água doce é um recurso natural de valor inestimável para os seres vivos. No entanto, é crescente o problema de escassez de água potável no Brasil pelo mau uso, assim como também pelo mau gerenciamento das bacias hidrográficas que tem ameaçado a qualidade da água, por isso buscou-se nas aulas de educação ambiental abordar os conteúdos sobre as propriedades da água e a sua importância para a vida de todos os seres do planeta Terra, e também os fatores que causam a poluição, além disso foi feita uma visita técnica à Estação de Tratamento de Água (ETA) e Estação de Tratamento de Esgoto (ETE) na qual os alunos compreenderam o caminho da água até as residências e o destino final das águas coletadas de esgotos, (Figura 1). 
Figura 1: Visita a Estação de Tratamento de Água (ETA) e Esgoto (ETE) de llha Solteira/SP.

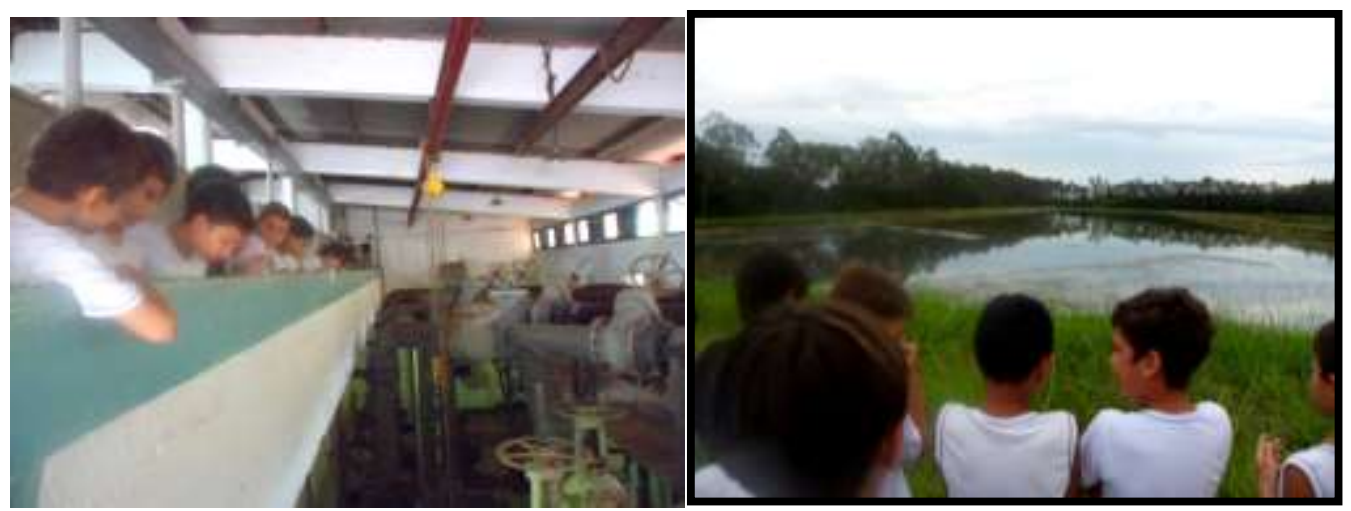

Fonte: Juliana de Assis, 2014.

Os problemas ambientais que contribuíram com a crise hídrica do Brasil e com a poluição das águas foram revisados e concluídos com a visita à Prainha de Ilha Solteira, durante a visita os alunos observaram a degradação da margem dos rios e a necessidade de restaurar o ambiente para a manutenção das espécies nativas da região. Entretanto, também foram trabalhadas as formas de preservação dos leitos de rios e mananciais por meio de aula teórica complementada por aula prática sobre Bacias Hidrográficas Brasileiras com a montagem de maquetes, (Figura 2).

Figura 2: Visita à prainha de llha Solteira/SP e a confecção de maquete de uma Bacia Hidrográfica.

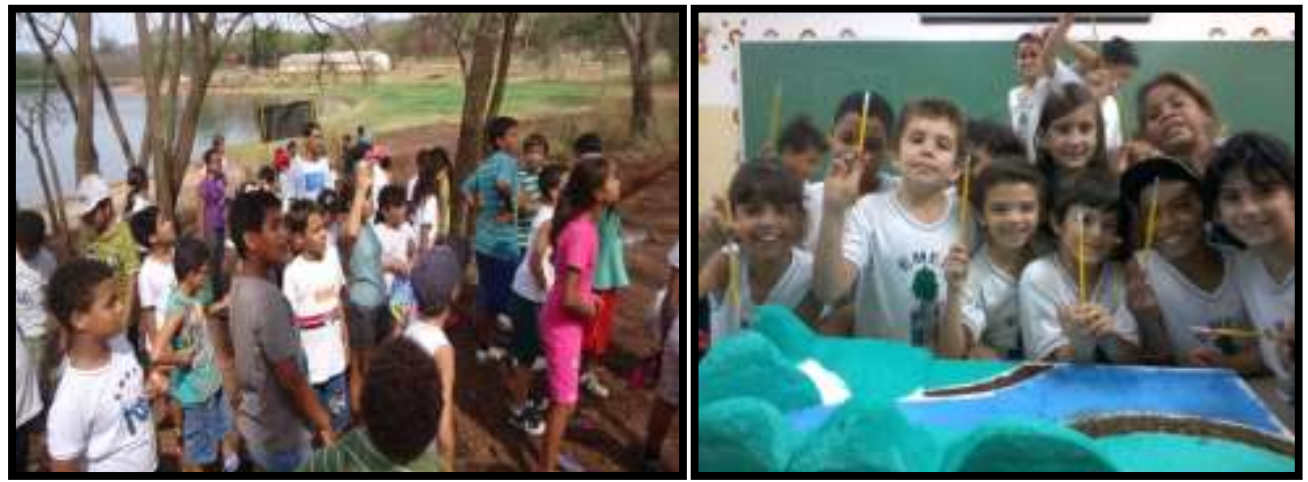

Fonte: Aline Patrícia Maciel e Juliana de Assis, 2012.

As matas ciliares são de extrema importância para evitar a erosão das margens de rios, córregos e lagos. Assim, nas aulas os alunos fizeram a simulação de chuva em uma maquete de mata ciliar e observaram a importância das raízes das plantas para a sustentação dos solos das margens dos leitos d’água. Após isso, 
foi feito o plantio de mudas de árvores em área próxima ao "Córrego sem Nome" do município de llha Solteira para o reflorestamento e preservação do local (Figura 3).

Figura 3: Aula prática sobre Mata Ciliar e plantio de mudas de árvores na margem de córrego em Ilha Solteira/SP.

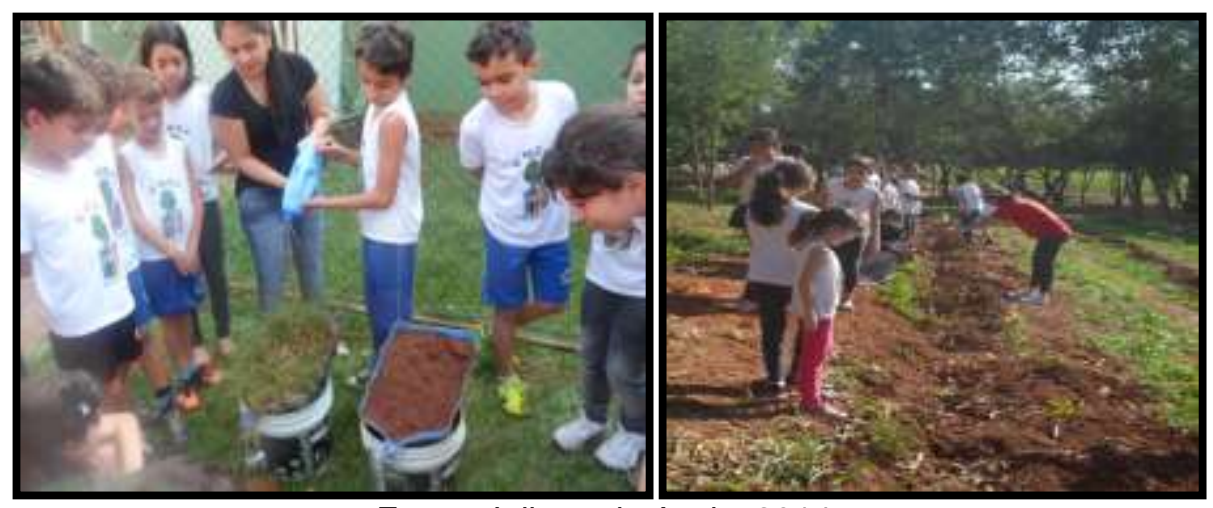

Fonte: Juliana de Assis, 2014.

\section{Energia}

Em parceria com a ELEKTRO, uma das maiores empresas de distribuição de energia do Estado de São Paulo, foi desenvolvido o "Projeto Elektro nas Escolas" para a conscientização das crianças sobre o uso eficiente e seguro da energia elétrica (Figura 4). As palestras aplicadas pela equipe técnica contribuíram para a aprendizagem dos alunos e também para as mudanças de hábitos destes. $O$ assunto foi finalizado com atividades sobre dicas de economia e com uma visita à Usina Hidrelétrica de llha Solteira (Figura 5).

Figura 4: Visita do caminhão do "Projeto Elektro nas Escolas" e equipe técnica.
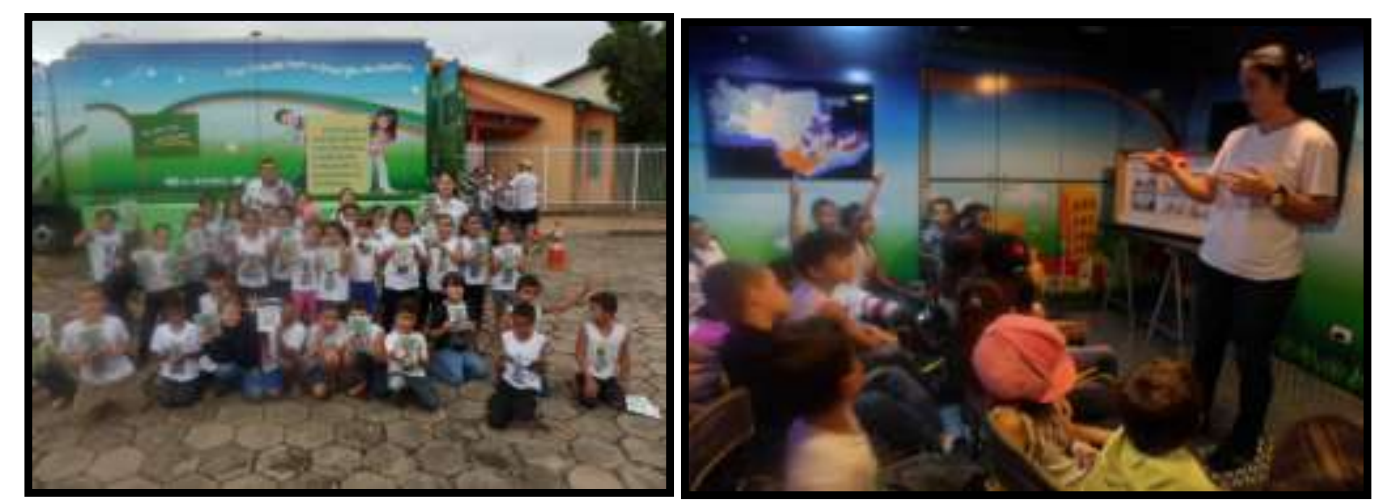

Fonte: Juliana de Assis, 2014. 
Figura 5: Visita à Usina Hidrelétrica de Ilha Solteira/SP

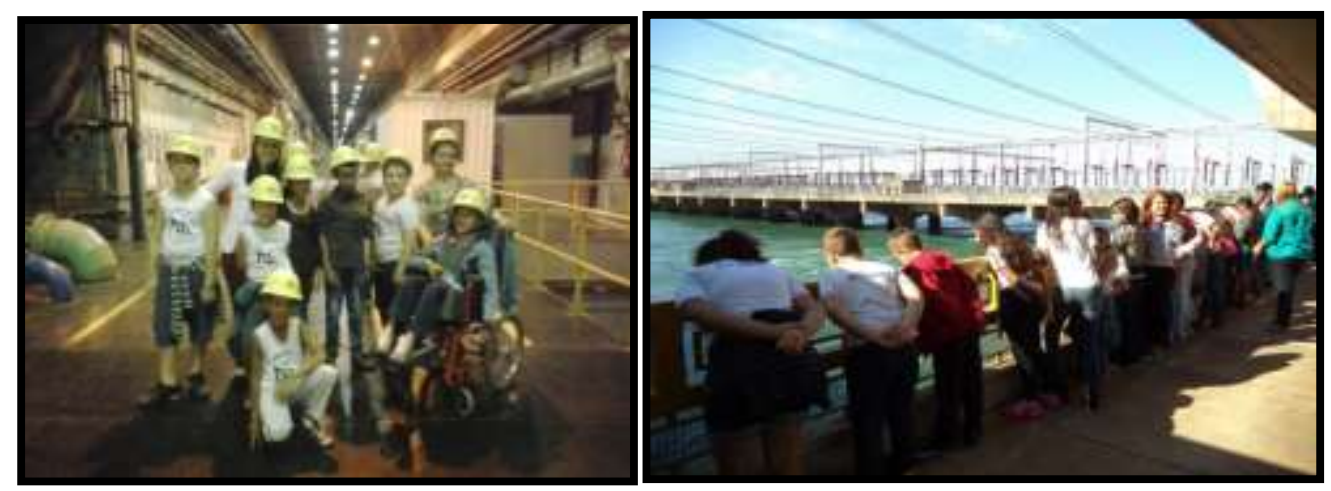

Fonte: Aline Patrícia Maciel, 2014.

\section{Flora e Fauna}

As queimadas e o desmatamento são os principais problemas que causam a redução das florestas de todo o mundo, aumentando a concentração de dióxido de carbono na atmosfera e o aquecimento do planeta Terra. Tais problemas afetam diretamente a vida dos animais. A fauna brasileira é uma das mais ricas do mundo por apresentar grande biodiversidade de espécies, porém algumas estão extintas e outras em risco de extinção.

Visto a importância destes problemas ambientais foram abordados durante as aulas os principais Biomas Brasileiros principalmente a fauna e flora característicos de cada (Figura 6).

Figura 6: Recorte e colagem de imagens de revista de animais e plantas característicos dos biomas brasileiros e plantio de plantas ornamentais nas EMEFs.

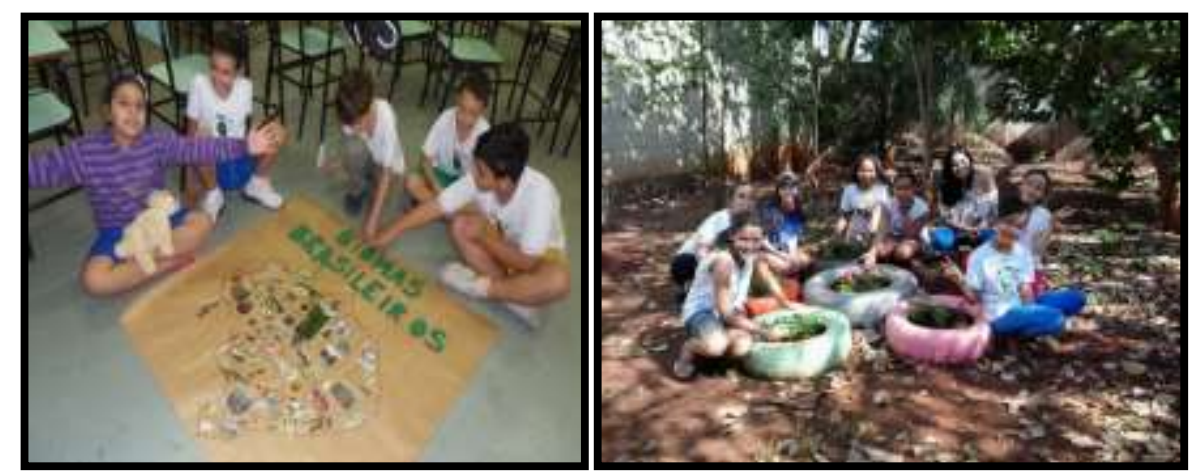

Fonte: Mariana Vasconcelos, 2014.

Já no espaço interno das EMEFs foi trabalhada a revitalização do ambiente escolar com o cultivo de plantas ornamentais em pneus reutilizados como vasos e 
além disso, também foram feitos plantios de hortaliças em garrafas pet em horta vertical, (Figura 7).

Figura 7: Cultivo de hortaliças em garrafas pet para produção de horta vertical.
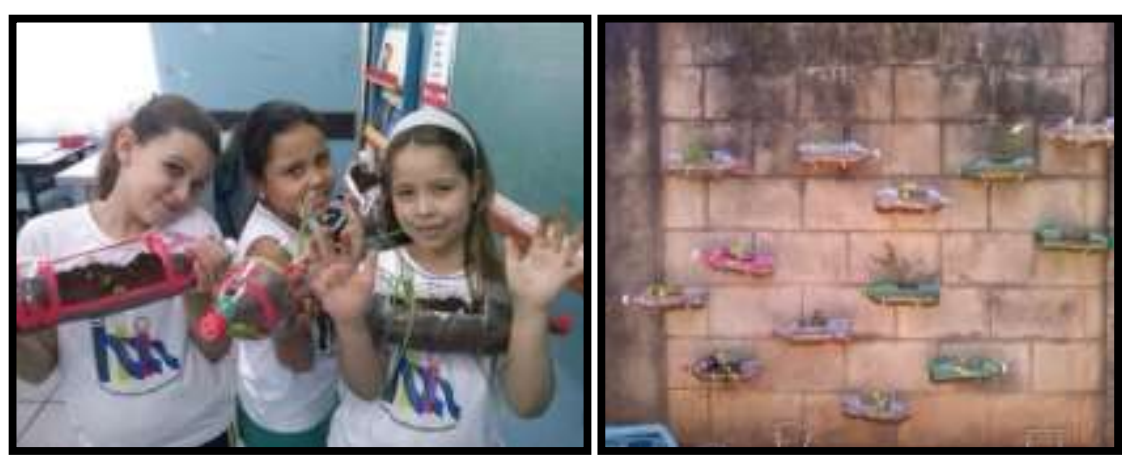

Fonte: Mariana Vasconcelos, 2014.

Existem diversos motivos que causam a extinção dos animais como, as caçadas, a falta de alimento e a incapacidade de reprodução. Entretanto, a preservação das espécies é fundamental para o equilíbrio da natureza. Assim, nas aulas objetivou-se conhecer a biodiversidade do mundo animal, os tipos de maus tratos dos animais, a exploração de espécies e as espécies em extinção complementando os estudos com a visita ao Zoológico de Ilha Solteira e ao Zoológico do município de São José do Rio Preto/SP (Figura 8).

Figura 8: Visita ao Zoológico de llha Solteira/SP e do município de São José do Rio Preto/SP.

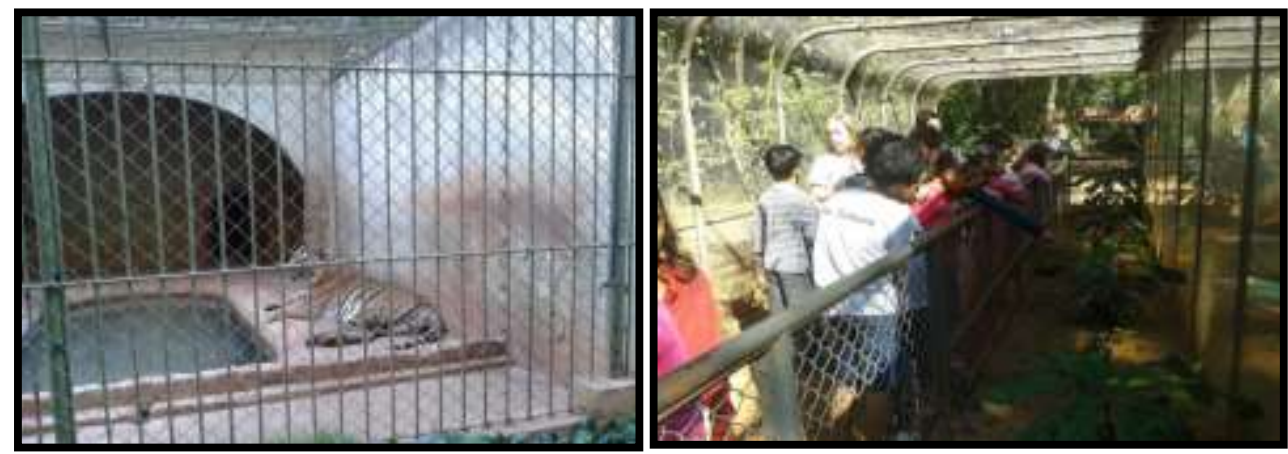

Fonte: Aline Patrícia Maciel, 2014.

\section{Trânsito}

No dia 25 de setembro data em que se comemora o Dia Nacional do Trânsito trabalhou-se a conscientização e a importância de um trânsito seguro por meio do Programa "Se essa rua fosse minha" em parceria com a guarda municipal 
de Ilha Solteira, proporcionando o desenvolvimento de valores, de posturas e atitudes corretas, que favoreçam o convívio social e a preservação de vidas. (Figura 9)

Figura 9: Atividades desenvolvidas sobre o Trânsito.

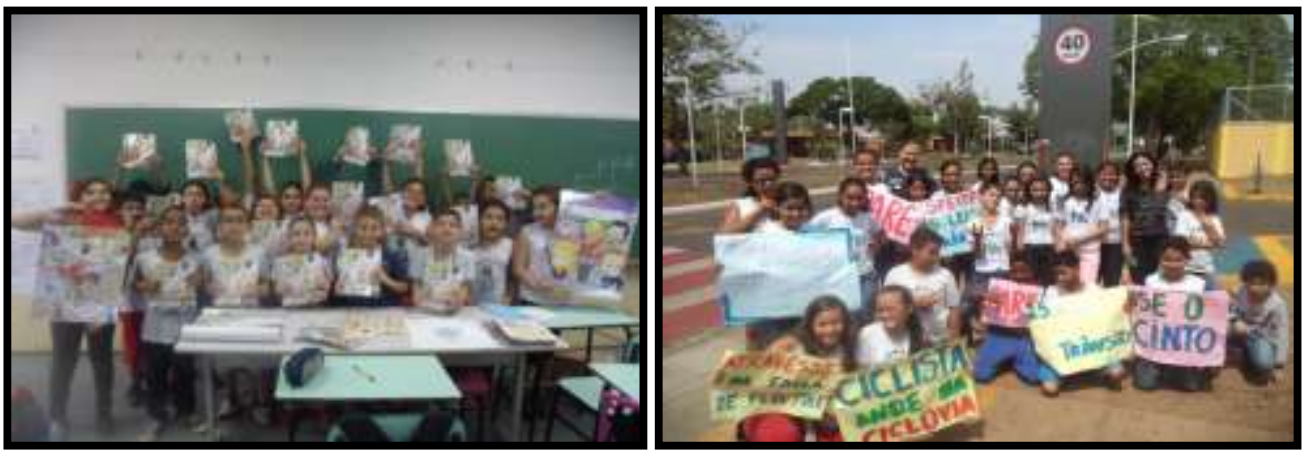

Fonte: Juliana de Assis e Aline Patrícia Maciel, 2014.

\section{O lixo e os três "R"}

A urbanização e a expansão das cidades desencadearam a grande produção de resíduos sólidos. Na busca de reduzir a quantidade de lixo e propor seu destino final de forma correta desenvolveu-se com os alunos a reflexão sobre a produção de lixo no planeta e a importância de se colocar em prática os 3 R's (Reduzir, Reutilizar e Reciclar). Desta forma, os alunos foram informados sobre o modo correto do armazenamento do lixo doméstico para facilitar a coleta seletiva e, além disso confeccionaram objetos e brinquedos com materiais recicláveis (Figura 10).

Figura 10: Reutilização de garrafas pet para confecção de brinquedos e bandeira do Brasil.
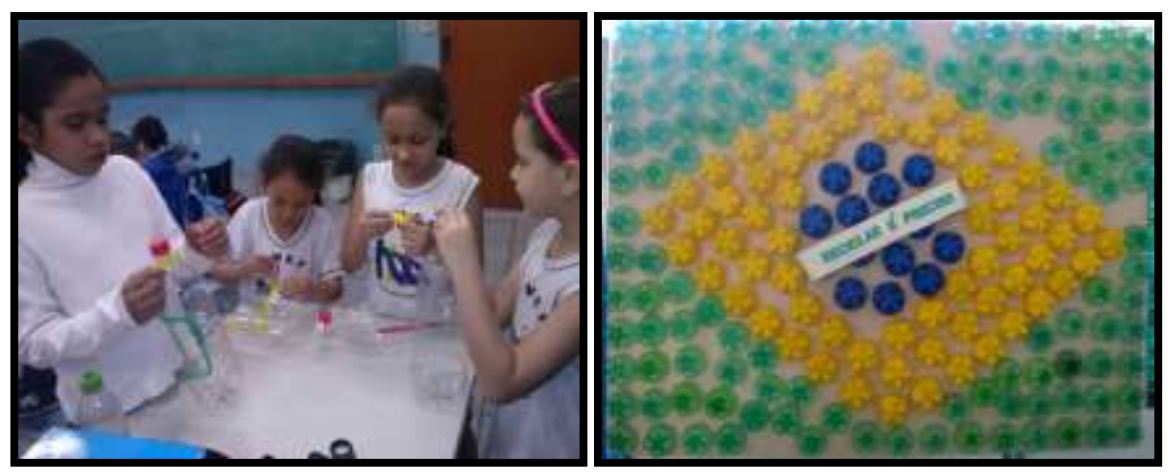

Fonte: Juliana de Assis, 2012 e Mariana Vasconcelos, 2014. 
O tema foi finalizado com a visita ao llha de Papel do município de llha Solteira, um projeto que oferece atividades socioeducativas através da fabricação de papéis artesanais com o uso de fibras vegetais e com o reaproveitamento de papéis recicláveis para a construção de novos papéis e objetos, (Figura 11).

Figura 11: Visita ao Ilha de Papel.
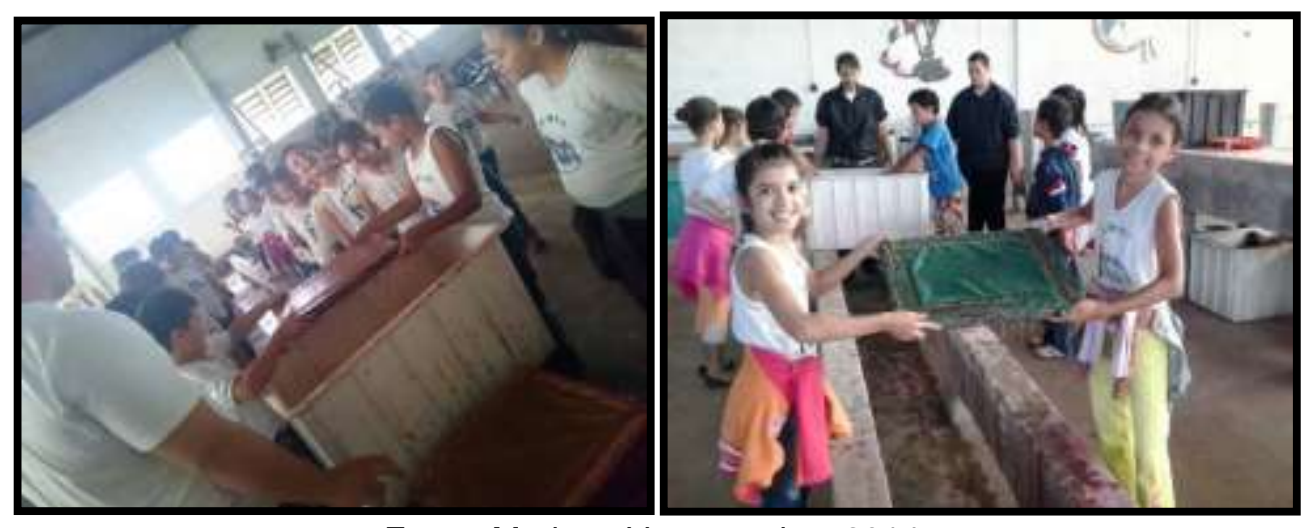

Fonte: Mariana Vasconcelos, 2014

\section{Alimentação Saudável}

Fazer uma alimentação correta e conhecer a origem e as técnicas de produção dos alimentos contribui para a manutenção de uma vida saudável. Por meio de conteúdos teóricos assim como também com aulas práticas como o plantio de hortaliças e com a degustação de frutas e legumes as crianças compreenderam a importância de ter uma alimentação colorida e nutritiva adotando uma alimentação saudável para a promoção da saúde (Figura 12).

Figura12: Degustação de Salada de Frutas

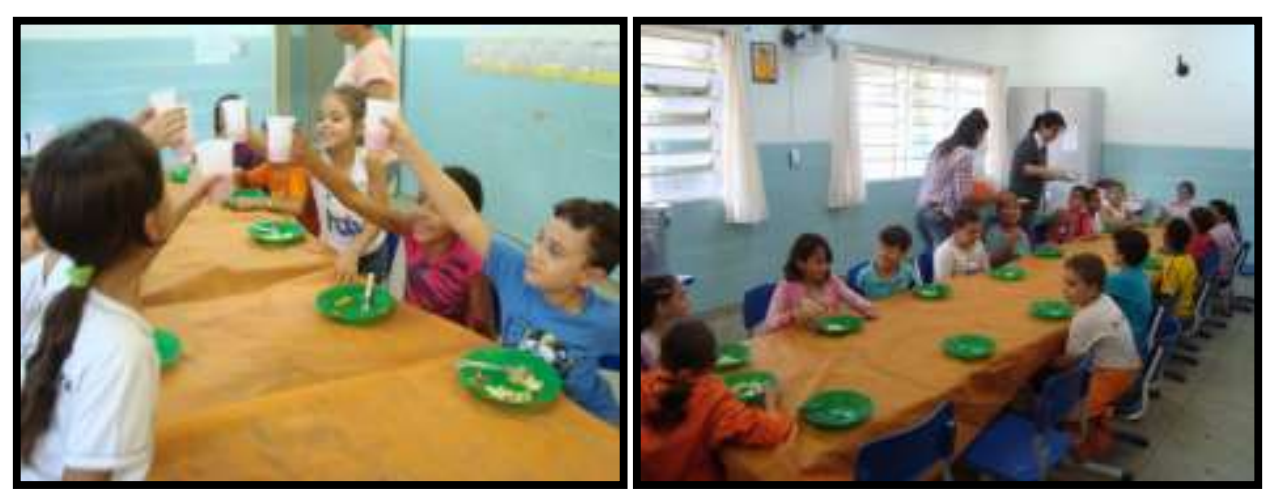

Fonte: Aline Patrícia Maciel, 2012. 


\section{Higiene Bucal e Corporal}

A higiene ambiental tem a ver com a saúde e uma vida saudável. Mais que cuidar do meio ambiente é importante também zelar pela saúde do corpo por meio de hábitos de higiene. Assim, também buscou-se estimular os alunos a conhecer e a cuidar do próprio corpo para se ter uma boa saúde e evitar as cáries (Figura 13).

Figura 13: Formas corretas de se fazer a higienização bucal.

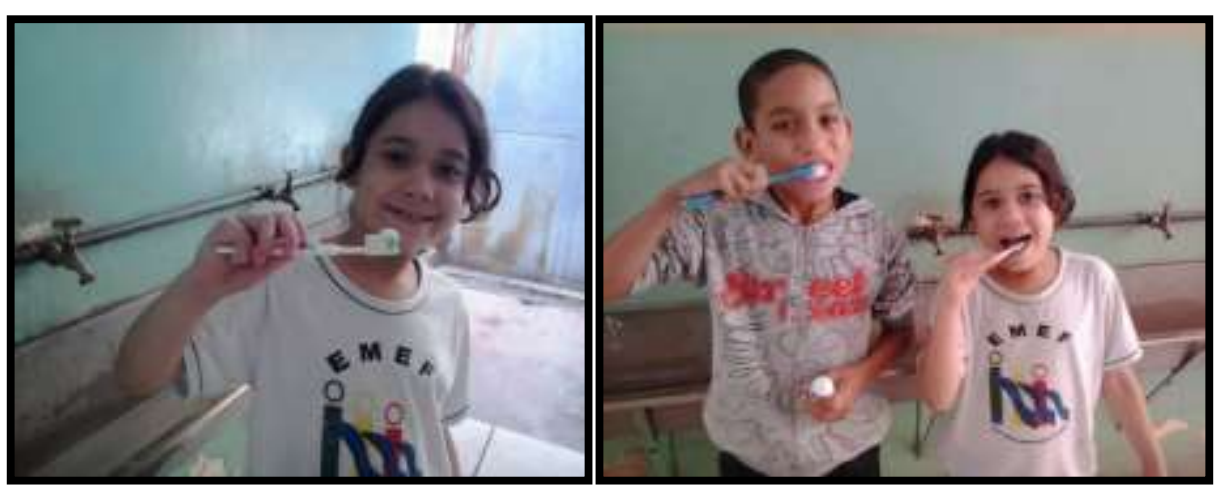

Fonte: Fonte: Aline Patrícia Maciel, 2015.

\section{Cidadania}

A EA contribui para a formação de cidadãos conscientes do seu papel no meio ambiente, isso inclui também o bom convívio entre todos os seres humanos. Assim, foram desenvolvidos os projetos de cidadania com o objetivo de estabelecer valores como o respeito ao próximo, em especial aos idosos e aos portadores de deficiências, desta forma contribuindo para a construção de uma cidadania ativa em defesa dos direitos iguais. O trabalho concretizou-se com a visita ao Centro Dia e a APAE (Associação de Pais e Amigos dos Excepcionais de llha Solteira), Figura 14.

Figura 14: Visita ao Centro Dia e a APAE.
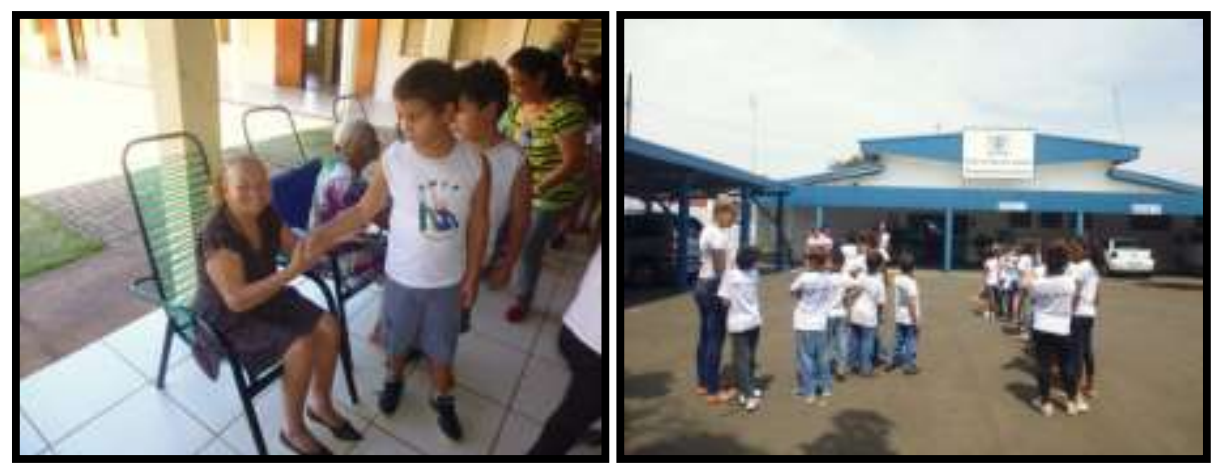

Fonte: Aline Patrícia Maciel, 2014.

Semana Municipal do Meio Ambiente 
Estabelecida pela Assembleia Geral das Nações Unidas, durante a Conferência de Estocolmo, o Dia Mundial do Meio Ambiente comemorado no dia 05 de junho não deve ser passado em branco. Sendo assim, as EMEFs celebraram essa data com palestras, passeatas, exposições de trabalhos escolares e apresentações de teatro e dança, para promover a conscientização dos alunos e cidadãos do município quanto aos problemas ambientais e a preservação dos recursos naturais, (Figura 15).

Figura 15: Passeata e apresentação de teatro na Semana Municipal do Meio Ambiente.

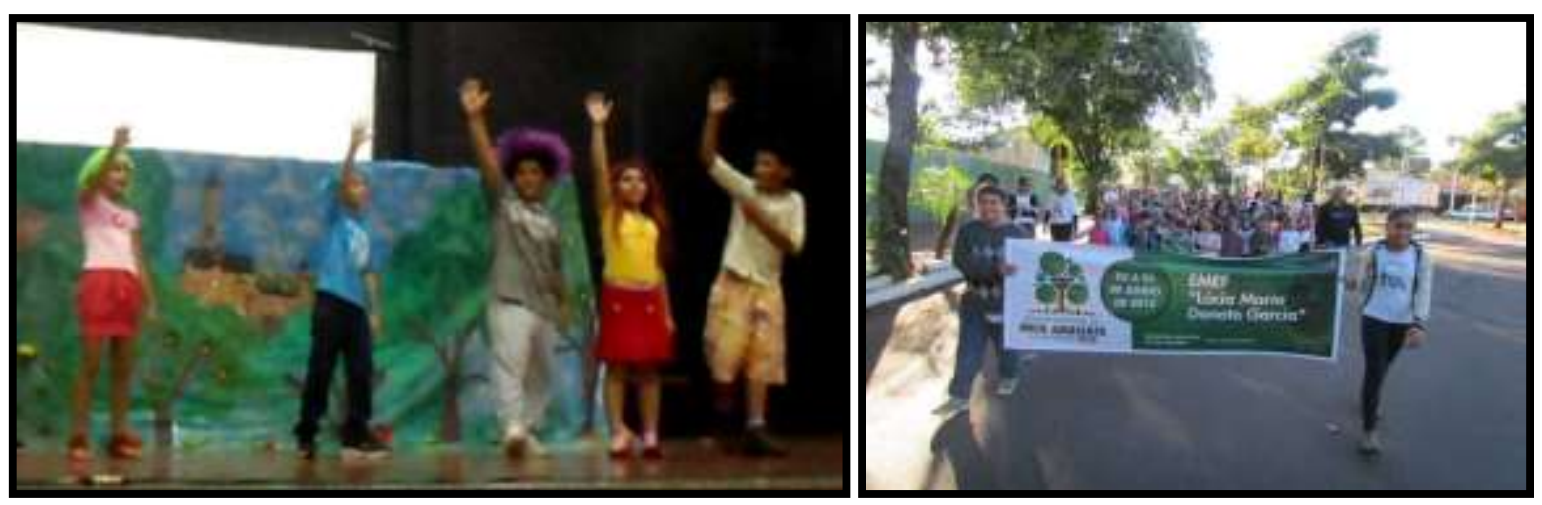

Fonte: Juliana de Assis, 2012 e Mariana Vasconcelos, 2014.

\section{CONCLUSÃO}

O futuro da humanidade depende da relação do homem com os recursos naturais que ainda restam, diante disso, o projeto de Educação Ambiental nas escolas municipais de llha Solteira/SP buscou promover atividades educativas para despertar nas crianças a responsabilidade de atitudes e comportamentos que contribuam para a preservação ambiental e a melhoria da qualidade de vida.

A prática da Educação Ambiental é relativamente complexa, pois é preciso haver a sensibilização e a conscientização dos alunos à qual nossa sociedade atual está inserida, os alunos aprendem, e principalmente, são instruídos a colocarem em prática no seu dia a dia.

O trabalho desenvolvido durante o Projeto apresentou bons resultados, pois possibilitou aos alunos a aprendizagem cognitiva, em relação aos principais problemas ambientais da atualidade, mediante as aulas teóricas complementadas com aulas práticas diferenciadas e com saídas de campo, pois levou os alunos a compreender todos os aspectos do meio ambiente com observações dentro e fora 
do ambiente escolar instigando-os a fazer questionamentos e propor soluções aos problemas ambientais.

Por meio das atividades realizadas foi possível observar que é fundamental a participação dos alunos durante as aulas de EA para que ocorra a sensibilização de forma efetiva e uma aprendizagem significativa.

Diante de tudo que foi exposto, pretende com a EA formar cidadãos com autonomia para desenvolver o pensamento crítico em relação as questões ligadas ao meio ambiente e promover mudanças de hábitos e valores para minimizar os impactos da sociedade de hoje sobre as futuras gerações.

\section{REFERÊNCIA}

ABÍLIO, Francisco José Pegado. Ética, Cidadania e Educação Ambiental, Meio Ambiente e Desenvolvimento - João Pessoa - PB, Editora UFPB, 2008.

BRANCO, Samuel Murgel. O Meio Ambiente em Debate. São Paulo: Moderna, 1988 BRASIL. Lei no 9.985, de 18 de julho de 2000. Dispõe sobre o Sistema Nacional de Unidades de Conservação da Natureza (SNUC). Brasília, DF: MMA/SBF, 2000. 32 p.

BRASIL. Política Nacional de Educação Ambiental. Lei 9795/99. Brasília, 1999.

BRASIL. Ministério da Educação. Secretaria de Educação Fundamental. Parâmetros Curriculares Nacionais: apresentação dos temas transversais. Brasília: MEC/SEF, 1998.

BRASIL. Constituição (1988). Constituição da República Federativa do Brasil. Brasília, DF, Senado, 1998

BRASIL. Lei Federal no 9.394, de 1996. Estabelece as Diretrizes e Bases da Educação Nacional. 1996. Disponível em http://www.planalto.gov.br/ccivil_03/leis/l9394.htm. Acesso em 10/05/2015.

INSTITUTO BRASILEIRO DE GEOGRAFIA E ESTATíSTICA - IBGE. 2007. Disponível em: http://www.ibge.gov.br/home/.

LUZZI, Dias. Educação Ambiental: Pedagogia, Política e Sociedade. In: PHILIPPI JR, A. e PELICIONI, M. C. F. (editores). Educação Ambiental e Sustentabilidade. Barueri, SP: Manole, 2005.

MARQUES, Mauricio Dias; DIAS, Lucas Seolin. Reflexões acerca da educação ambiental

Conscientizada em ações efetivas e práticas. IX Fórum Ambiental da Alta Paulista, v. 9, n. 6, 2013, p. 36-53. 